\title{
FACTORS INFLUENCING CLOUD COMPUTING ADOPTION-COMPARED REVIEW AND A 4-M RECOMMENDATION
}

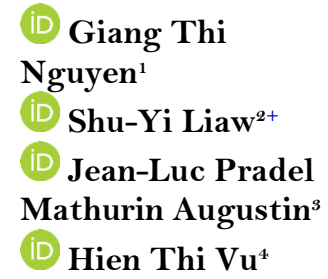

Article History

Received: 10 February 2021 Revised: 15 March 2021 Accepted: 20 April 202 Published: 25 May 2021

\section{Keywords}

Cloud computing Technology category Organization category Environment category Innovation category Technology readiness Top management support Relative advantage Security concern.

\author{
Department of Tropical Agriculture and International Cooperation, \\ National Pingtung University of Science and Technology, Taiwan; \\ Department of Economics and Rural Development, Thainguyen University of \\ Agriculture and Forestry, Vietnam. \\ Email:ngryenthigiang@tuaf.edu.vn Tel: (+886)0905435106 \\ ${ }^{2}$ Department of Business Administration, Computer Centre, National \\ Pingtung University of Science and Technology, Taiwan. \\ Email:syliaw@mail.npust.edu.tw Tel:+886-8-7703202(ext.6140) \\ ${ }^{s}$ Department of Tropical Agriculture and International Cooperation, \\ National Pingtung University of Science and Technology, Taiwan. \\ Email:pradelaugustin@gmail.com Tel:(509)3716-4085 \\ ${ }^{\text {}}$ Department of Economics and Rural Development, Thainguyen University \\ of Agriculture and Forestry, Vietnam. \\ Email: vuthihien@tuaf.edu.vn Tel: (+84)976932426
}

\section{ABSTRACT}

Cloud computing is increasingly popular in firms around the world. However, there are limited review studies focusing on cloud computing applications in companies. Thanks to the application of the technology-environment-organization (TOE) framework and diffusion of innovation (DOI) theory, this research unearths the factors influencing the decision-making process in cloud computing between developed and developing countries. The review further captures the stonewalls of cloud computing adoption enlisted in literature. Systematic review methods were applied to analyze relevant articles during the 2011 to 2020 period. The findings reveal that 36 factors impact organizational cloud computing adoption, out of which 21 factors occur in both developed and developing economies. The remaining 15 factors differ between developed and developing countries. Five of these factors that reveal a strong impact on cloud adoption by firms are Technology readiness, Top management support, Relative advantage, Costs, and Security, privacy and ethics concern. The literature-based limitations found in previous studies on cloud computing adoption in firms include research area, data collection technique, research methodology and theoretical models, and research subject. These challenges were organized in a 4-M recommendation for future research.

Contribution/Originality: This study contributes to the existing literature a comprehensive picture of factors influencing the application of cloud computing in firms between developed and developing countries. Hence, the results of this study can enhance managers', and suppliers' understanding of the main factors affecting the adoption of cloud computing in organizations.

\section{INTRODUCTION}

Cloud computing refers to a breakthrough phenomenon in information technology area that attracts the attention of many scientists, businesses people, and governments [1]. The application of cloud computing is associated with numerous benefits for enterprises such as cost savings, increased flexibility and easy access to data sources [2-5]. It enhances companies' ability to resolve the disadvantages embedded in traditional information 
technology [6]. The application of this new technology advances businesses' competitive advantage agenda, allowing for the exploitation of assorted opportunities within the market economy.

In view of the vigorous globalization process, establishment and adoption of strong technology are critically vital for both the national economy and microenterprises development [7]. The application of new technologies encounters several challenges. Despite the significantly large investment cost associated with the relevant infrastructures and the capacity of human resources, application of new technologies must overcome challenges related to information security and risks during use [4, 8-10]. Firms must carefully consider such hurdles before selecting and applying specific new technology. In recent years, the literature has focused on factors influencing the cloud computing application in most of the developed countries including USA, England, and Australia [11-13] and developing countries such as Malaysia, China, Indonesia, and India [14-17]. This specialization of premise creates a lack of a comprehensive outlook that bring solid analysis. Therefore, the objectives of this study are to:

1) Provide a comprehensive picture of factors influencing the decision to apply cloud computing in firms between developed and developing countries.

2) Identify the challenges observed in previous studies, proposing a 4-M recommendation for future research.

This paper is divided into six main parts, starting with the introduction that captures the research objective. Then an overview of related literature is presented. The following section describes the research methodology while the findings are illustrated in the fourth section. The managerial implications are then described in the fifth part. The last section addresses the conclusions and limitations.

\section{THEORETICAL BACKGROUND}

\subsection{Definition of Cloud Computing}

Several perspectives generally focus on specifications related to cloud computing. According to Buyya, et al. [18], cloud computing denotes "a type of parallel and distributed system consisting of a collection of interconnected and virtualized computers that are dynamically provisioned and presented as one or more unified computing resources based on service-level agreements established through negotiation between service provider and customer". Cloud computing is a model that provides computer resources to users, and is considered a technological service consisting of hardware and software. With the availability of internet connection cloud resources are easily accessible by users any time [19,20]. Services offered by cloud computing focus on three major types including Infrastructure as a Service (IaaS), Platform as a Service (PaaS), and Software as a Service (SaaS) [21-24]. IaaS entails a series of computing infrastructure including servers, operating, network, and storage systems. The biggest advantage of using IaaS is that organizations can scale up and down depending on their needs and capabilities. Hence, organizations with large data storage sources often choose to use IaaS [24]. PaaS provides customers with cloud infrastructure that is used to create applications that can be customized and developed to suit their needs [25]. SaaS is a service through which customers rent applications that run on cloud infrastructure from cloud service providers and use it directly via the internet environment. Customers neither need to install any other software, nor manage cloud infrastructures such as networks, servers and storage systems [10, 24]. Moreover, when applying this service, the customer's data is stored on the server and data security is guaranteed. Recently, the benefits of cloud computing and information technology have prompted the extensive exploitation of such new technologies by various researchers and organization [22].

\subsection{The Technology-Organization-Environment (TOE) Framework}

TOE framework analyses factors affecting adoption of new information technology. The framework consists of three pillars, namely, technology, organization, and environment [26]. The technology pillars define some factors related to the tools, software, IT infrastructure, etc. that can affect individual's or organizations' application for cloud computing. The organizational category captures the firm's ability to gain expertise in the use of various 
resources to support the application of firm information systems. Environmental components include various industrial factors such as market factors, competitors, and vendors' support, directly or indirectly affecting the operation of enterprises. These are external environmental factors that impact the business's decision to implement new technology [26, 27]. TOE framework has been used by many researchers. Safari, et al. [28] applied it to explore issues that affected SMEs cloud computing application in Iran. In that study, questionnaires were sent to 200 Iranian SMEs via the internet of which 92 usable responses were received. Data was analyzed by partial least square (PLS) techniques. Moreover, Alshamaila, et al. [12] defined the factors related to cloud adoption in SMEs in Northeast of England using TOE framework in data collected from 15 main staffs and service suppliers.

\subsection{Diffusion of Innovation (DOI) Theory}

DOI is a popular model applied in many studies related to Information Systems (IS). The innovation model is applied in enterprises following five steps, i.e., knowledge, persuasion, decision, implementation, and confirmation. It proposes that the characteristics related to the application of innovations in businesses consists of relative advantage, compatibility, complexity, observability, and trialability [29, 30]. The choice of applying for an invention includes three factors. Firstly, the individual factor defines leadership attitude towards application for new technology. Secondly, the organizational element means the internal aspects consisting of coordination, support among employees in the enterprise, concentration, and complexity when applying new technology. The final element is external factors. Rogers [29]; Oliveira, et al. [31]. Mokwena [32] adopted DOI theory and collected data from 119 South African SMEs. The findings indicated that some enterprises did not apply SaaS because they did not have knowledge about it. The research also showed that cost and complexity factors were the biggest influences on the decision to apply SaaS in firms.

\section{METHODOLOGY}

\subsection{Articles Selection}

This study uses the systematic review method, TOE framework and DOI theory for exposition of factors influencing enterprises in countries that are developed and developing when they adopt cloud computing. The study for analysis was further applied to identify the literature-based deterrents of cloud computing. The TOE framework and DOI theory were chosen for two reasons. Firstly, TOE framework is a more complete explanation of the application of innovation in businesses [31]. Secondly, TOE is popular in cloud computing research. Specially, 27 out of 48 studies have used the theoretical models to analyze the factors affecting enterprises' decision to apply cloud computing, out of which, 19 studies used the TOE framework. Twelve studies have used the single TOE framework and 7 studies used the TOE framework in combination with another research theory like DOI or Technology Acceptance Model (TAM). However, to fully explain the factors that affect enterprise application and innovation processes is difficult when using one theory [33]. Hence, this research decided to incorporate the TOE framework and the DOI theory. The systematic review is an evaluation method, synthesizing studies and focusing on specific content by providing strong, transparent, and coherent evidence to increase the generalizability and applicability of research findings [34, 35]. In the first step, this study identified relevant publications by searching the following keywords: "factors" and "affecting" and "adoption" and "cloud computing" and "firms" and "developed country" and "developing country". The search process revealed that the majority of articles appeared in Google Scholar, Emerald Insight, Spring Link, Science Direct, IEEE Explore. 1098 articles were downloaded from this step. In the second step, available data filtering tools were used to reduce the number of articles that were not included in the study based on year of publication, language and type of article (publication during 2011-2020, English language, two type of articles include review and research articles). A total of 706 articles were remaining after this step. The third step, authors read titles and summaries of articles to remove unrelated articles, 326 articles were rejected in this step. In the next step, after fully reading the contents of the remaining 380 articles, 332 articles 
were rejected. Finally, 48 articles (2 reviews and 46 research articles), specific to factors in relation to the application of cloud computing in firms, were used for this study. They were extracted from the following databases Science Direct (21), Google Scholar (14), Emerald Insight (5), IEEE Explore (4), Spring Link (4). The publication by year in developed and developing country are illustrated in Figure 1.

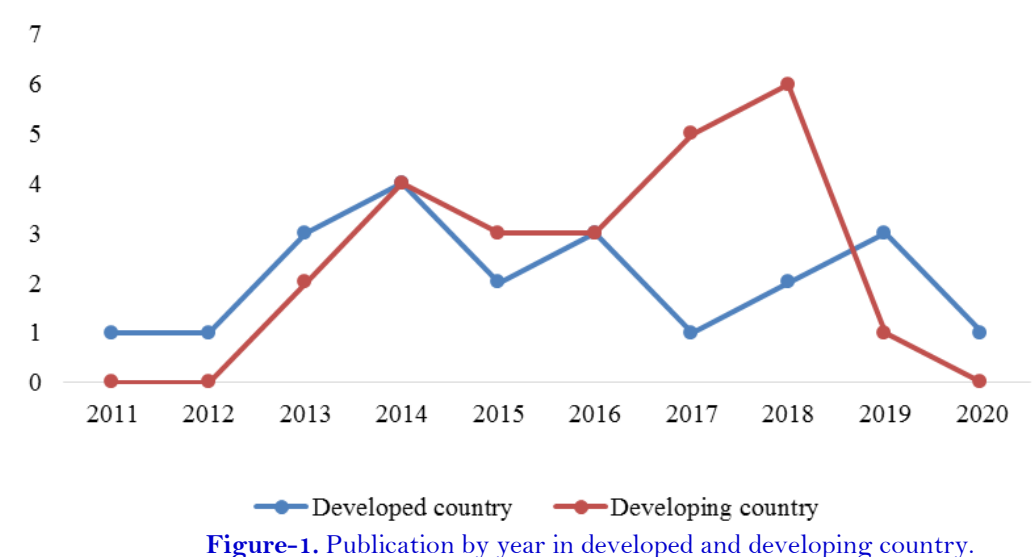

\subsection{Articles Analysis}

The factors influencing the decision-making process in cloud computing in the previous studies were summarized using Excel software. NVivo 12 software was used to identify the relative importance of factors affecting cloud computing adoption in previous research. The study research process is shown in Figure 2.

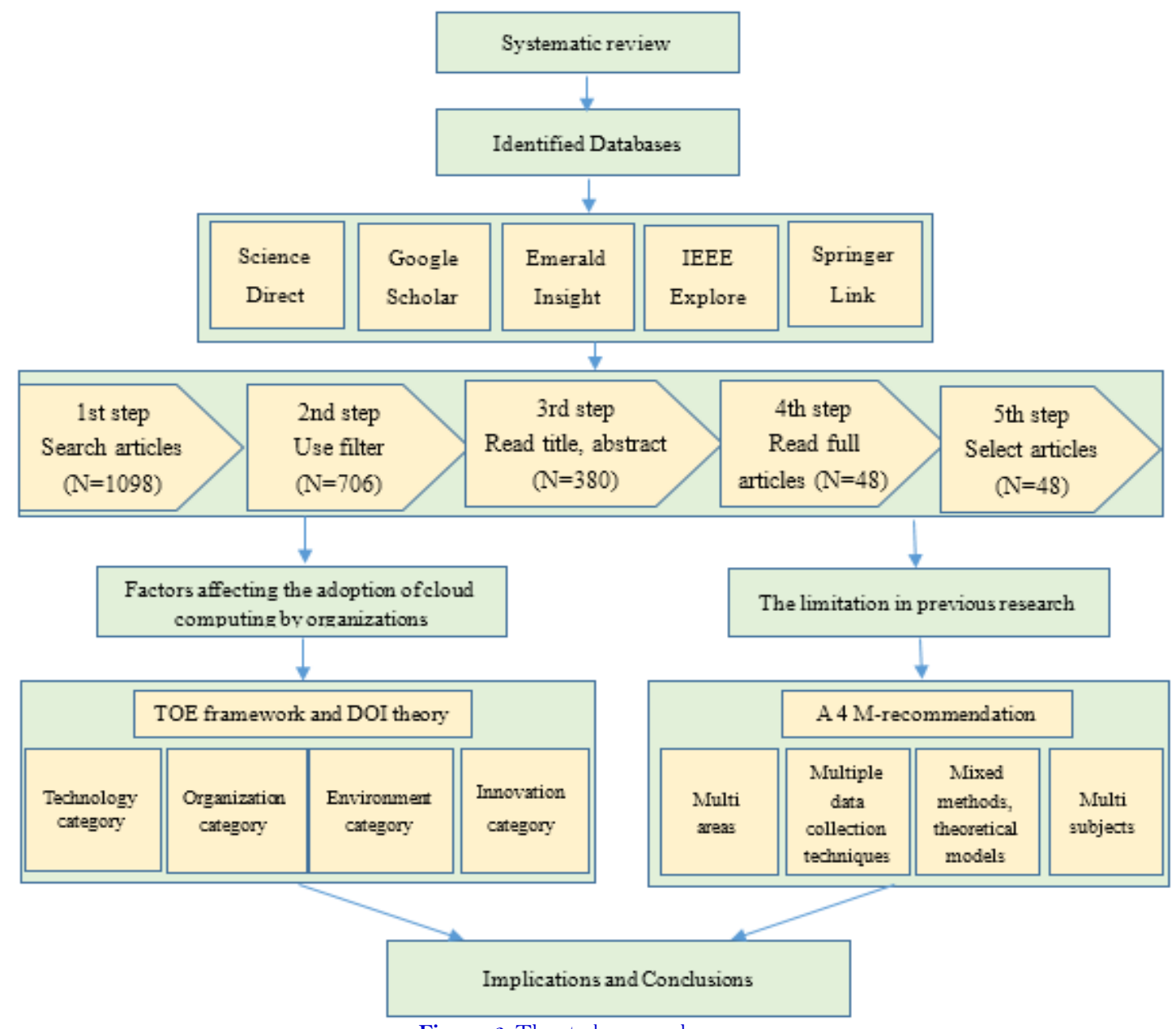

Figure-2. The study research process. 


\section{FINDINGS}

\subsection{Factor Affecting the Adoption of Cloud Computing by Organizations}

This paper revealed 36 factors affecting cloud computing adoption in firms. TOE framework and DOI theory divided them into four main categories, i.e., technology, organization, environment, and innovation, shown in Table 1, Table 2, Table 3, and Table 4 .

In Table 1, based on findings, the technology category is the largest, consisting of 13 factors. Most factors were found in both developed and developing countries embracing Technology readiness, Relative advantage, Security, privacy and ethics concern, Ease of use and convenience, Reliability, Risk analysis, and Previous technological experience.

Table-1. Classification of factors for the technology category.

\begin{tabular}{|c|c|c|c|}
\hline \multirow[t]{2}{*}{ Category } & \multirow[t]{2}{*}{ Factors } & \multicolumn{2}{|c|}{ References } \\
\hline & & Developed countries & Developing countries \\
\hline \multirow[t]{13}{*}{ Technology } & 1) Technology readiness & {$[12,13,31,36-40]$} & {$[7,14,15,28,41-47]$} \\
\hline & 2) Security, privacy and ethics concern & {$[48-53]$} & $\begin{array}{c}{[17,42-44,46,49,52-} \\
57]\end{array}$ \\
\hline & 3)Ease of use & {$[49,52,58]$} & {$[17,43,44,49,52]$} \\
\hline & 4) Reliability & {$[48]$} & {$[17,55]$} \\
\hline & 5) Previous technological experience & {$[12]$} & {$[17]$} \\
\hline & 6) Risk analysis & {$[59]$} & {$[42,43,46,59]$} \\
\hline & 7) Elasticity & & {$[17]$} \\
\hline & 8) Ecological sustainability & & {$[17]$} \\
\hline & 9) Data sensitivity & & {$[28]$} \\
\hline & 10) Uncertainty and Geo-restriction & {$[12]$} & \\
\hline & 11) Scalability and flexibility & {$[38]$} & \\
\hline & $\begin{array}{l}\text { 12) Information processing } \\
\text { requirements }\end{array}$ & {$[11]$} & \\
\hline & 13) Information processing capability & {$[11]$} & \\
\hline
\end{tabular}

Of all technology contexts, Technology readiness, Security, privacy and ethics concerns, and Ease of use have the biggest impact on adopting cloud computing in firms. This shows that issues related to information technology infrastructure, the availability of qualified information technology professionals, data security, the reputation of businesses, easy access to data from different devices at different locations are a top concern for enterprises when deciding to apply cloud computing as were similarly mentioned in some previous research [13, 31, 38].

Moreover, the study shows that some factors such as Elasticity, Ecological sustainability, and Data sensitivity were discussed in developing countries that are facing many challenges such as capital and lack of information technology experts [7]. Due to limited economic and human characteristics of resources, when choosing to apply cloud computing, enterprises in developing countries are concerned about sustainability, and elasticity [42, 43, 46]. In contrast, companies in developed countries care about Uncertainly, Scalability and Flexibility, Information processing requirements and Information processing capability factors when they choose to apply cloud computing. Uncertainty explains the limitations of knowledge, resources, so it is difficult to accurately predict future potential results. There are three types of uncertainties such as environmental, organizational, and uncertainty. Hence, firms need to carefully consider the types of uncertainty before deciding to apply cloud computing [11]. The scalability and flexibility of information infrastructure systems, processing requirements, and enterprise processing capabilities are also important factors that contribute the decision by firms to apply cloud computing. Analyzing these factors will help companies better understand the requirements and the ability to process information [11]. There are few studies that mention these factors. In the future, these factors should be explored in studies in developing countries.

In Table 2, the organizational category (Top management support, Organization readiness, Knowledge and training, Size of organization, Trust and Sharing and collaboration) is presented in developed and developing countries. The three factors with the highest number of articles mentioned were top management support, 
organization readiness, and knowledge and training. Top management support refers to a person or group of people who make important decisions in a company. They will decide whether or not to adopt new technologies and decide to invest the resources needed to apply the new technology [16]. Organization readiness refers to company resources such as finance, IT professionals, and infrastructure when the company applies cloud computing. Knowledge and training refer to the respondents' understanding of some aspects such as benefits, barriers, and how to apply cloud computing in their firms. These factors influence greatly on companies decisions for cloud computing adoption $[17,18]$.

Table-2. Classification of factors for the organization category.

\begin{tabular}{|c|c|c|c|}
\hline \multirow[b]{2}{*}{ Category } & \multirow[b]{2}{*}{ Factors } & \multicolumn{2}{|c|}{ References } \\
\hline & & Developed countries & Developing countries \\
\hline \multirow[t]{9}{*}{ Organization } & 1) Top management support & $\begin{array}{c}{[12,31,37-39,48,52,60-} \\
62]\end{array}$ & $\begin{array}{c}{[3,7,14,16,17,42,43,46,} \\
52,54,56,57,63]\end{array}$ \\
\hline & 2) Organization readiness & {$[36,48]$} & {$[3,15-17,43,44,47]$} \\
\hline & 3) Knowledge and training & {$[64,65]$} & {$[3,16,17,28,66-68]$} \\
\hline & 4) Size of organization & {$[12,31,37,48,62]$} & {$[16,17]$} \\
\hline & 5) Trust & {$[51,58,69]$} & {$[42,43]$} \\
\hline & 6) Sharing and collaboration & {$[49,61]$} & {$[49]$} \\
\hline & 7) IT governance and risks & {$[13]$} & \\
\hline & 8) Contracting and transaction risks & {$[13]$} & \\
\hline & 9) Strategic issues & {$[50]$} & \\
\hline
\end{tabular}

In this category, there were three factors mentioned in research in developed countries: IT governance and risks, Contracting and transaction risks, and Strategic issues. According to Parent and Reich [70] when choosing to apply new technology, customers may have problems related to application availability, security, and efficiency. In order to deal with the risks encountered in the above problems, customers need to develop IT governance. Additionally, due to companies' lack of understanding, some providers may cheat when providing cloud services; they may offer customers less functionality than agreed upon [13]. Hence, contracting and transaction risk factors are important factors that organizations should consider when applying cloud computing to minimize risks. Strategic issues refer to a businesses need to have solutions to solve problems that occur in the application of cloud computing [50]. However, these factors have only very limited mentions in research in developed countries. They were not mentioned in developing countries. Therefore, in the future, these factors should be mentioned in the application in developing countries.

In Table 3, environment category was identified. Vendor support, Competitive pressure, and Industry pressure are presented in both developed and developing countries and they are the three factors that have the greatest influence on the decision to adopt cloud computing in this category. Vendor support indicates that the support of suppliers is important to help organizations easily apply cloud computing technology, as well as easily solve difficulties encountered during implementation [12, 28]. Competitive pressure is the terminology used to define to what extent competitors influence the organization's decision to adopt new technologies [18]. According to Levenburg, et al. [71] firms operating within various industries can be influenced by the use of information system innovation. Furthermore, some studies proved that in the financial field, businesses use computers more than in other fields [72, 73].

On the other hand, when applying cloud computing, firms in developed countries pay attention to a number of factors such as Market scope and Quality of services. Market scope refers to the company expanding its scope of activities to domestic and international regions [74]. This can lead to increased costs for storing and searching for information [75]. Applying cloud computing is efficient for businesses and helps businesses less geographically dependent [12]. Quality of services is a factor that has a significant influence on enterprise's agreement to use cloud 
computing [51]. In contrast, research in developing countries was focused on factors such as Environmental readiness, Governmental support, and External pressure.

Due to the characteristics of financial conditions as well as limited high-quality human resources when applying cloud computing to firms in developing countries, they are very interested in the support of external factors as well as support from government. Governments in developing countries should have more policy mechanisms to support businesses applying cloud computing [28].

Table-3. Classification of factors for the environment category.

\begin{tabular}{l|l|c|c}
\hline \multirow{2}{*}{ Category } & \multirow{2}{*}{ Factors } & \multicolumn{2}{|c}{ References } \\
\cline { 2 - 4 } Environment & Developed countries & Developing countries \\
\cline { 2 - 4 } & 2) Competitive pressure & {$[12,37,38,65,76,77]$} & {$[3,7,28,47,54,57]$} \\
\cline { 2 - 4 } & 3) Industry pressure & {$[10,48,62]$} & {$[3,28,56,57]$} \\
\cline { 2 - 4 } & 4) Partner pressure & {$[40,62]$} & {$[43]$} \\
\cline { 2 - 4 } & 5) Market scope & {$[12]$} & {$[56]$} \\
\cline { 2 - 4 } & 6) Quality of services & {$[51]$} & {$[15]$} \\
\cline { 2 - 4 } & 7) Environment readiness & & {$[17,28,57]$} \\
\cline { 2 - 4 } & 8) Governmental support & & {$[45,54]$} \\
\cline { 2 - 4 } & 9) External pressure & & \\
\hline
\end{tabular}

The classification for innovation category including Relative advantage, Cost, Compatibility, Complexity, and Trialability are summarized in Table 4.

These factors are present in both developed and developing countries. According to Rogers [78], relative advantage is "the degree to which a technological factor is perceived as providing greater benefit for firms". Cost refers to cost that companies pay their suppliers when they apply cloud computing. A number of studies show that businesses can reduce costs when they choose to apply cloud computing Ming, et al. [14]; Oliveira, et al. [31]; Gupta, et al. [49].

The perception that technology is highly reliable and meets the requirement of existing users defines the concept of compatibility [78]. Complexity conveys that an increase in the cost of adoption simultaneously increases with the level of complexity. Therefore, complexity hinders cloud computing adoption due to its high cost. Trialability refers to the aspect of trying the product before companies decide to use it. These five factors in the innovation category are mentioned by many previous studies in developed and developing countries Table 4. This shows that these factors are important and influence the decisions of enterprises to adopt cloud computing.

Table-4. Classification of factors for the innovation context

\begin{tabular}{l|l|c|c}
\hline \multirow{2}{*}{ Category } & \multirow{2}{*}{ Factors } & \multicolumn{2}{|c}{ References } \\
\cline { 2 - 4 } & Developed countries & Developing countries \\
\hline Innovation & 1) Relative advantage & {$[12,31,36,37,39,48,58,62,69,76]$} & {$[3,17,28,44,54,57]$} \\
\hline & 2) Cost & {$[13,31,37,38,49,52,53,61]$} & {$[14,17,32,46,49,52,53$,} \\
& & {$[12,37,39,52]$} & {$[3,7,17,28,52,57]$} \\
\hline & 3) Compatibility & {$[31,37,40,48]$} & {$[3,32]$} \\
\hline & 4) Complexity & {$[12,37,38]$} & {$[7,17,32]$} \\
\hline
\end{tabular}

Based on the frequency of the factors influencing the decision to apply cloud computing in 48 research articles, word clouds generated by NVivo 12 software in Figure 3.

The word clouds show that the higher the frequency of a word, the larger its corresponding font. This figure illustrates that Technology readiness, Top management support, Relative advantage, Security, privacy and ethics concern, and Costs are the factors most mentioned in previous studies in both developed and developing countries. 


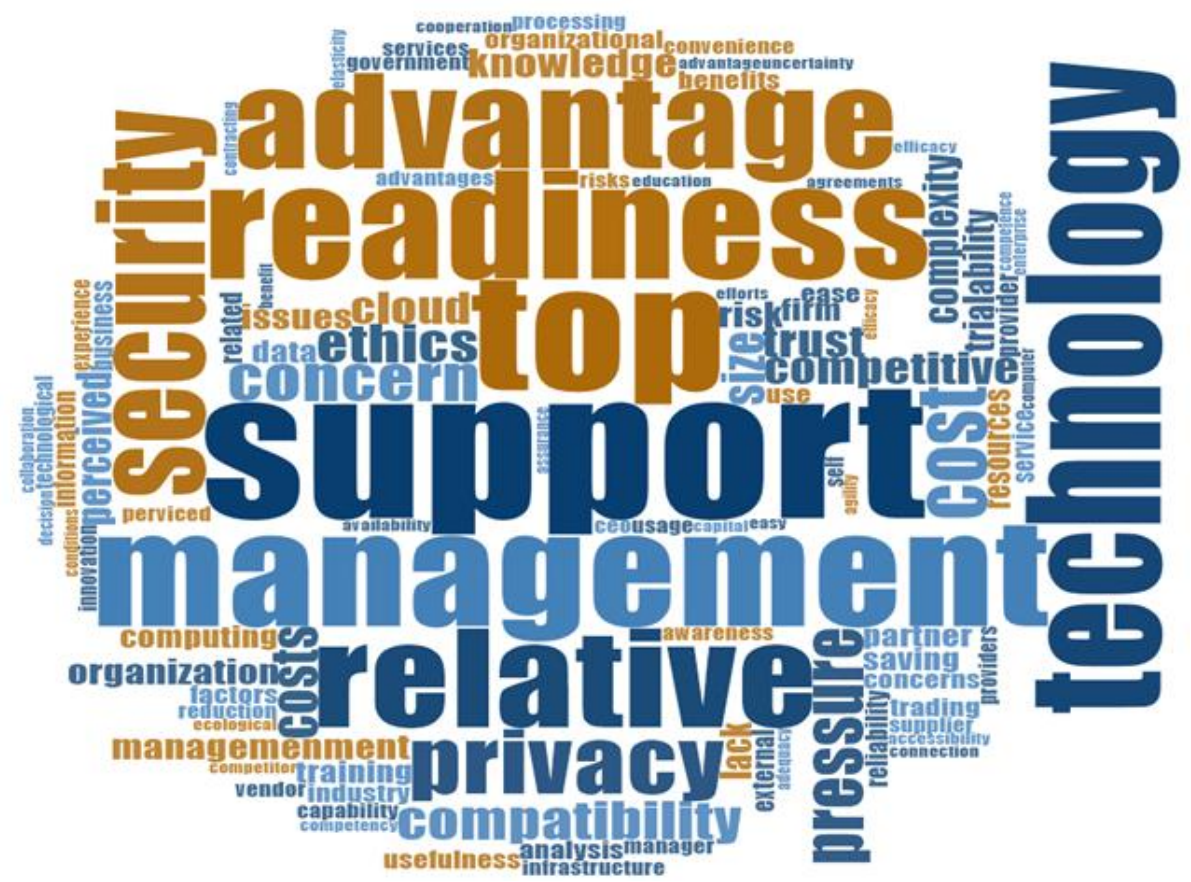

Figure-3. Word cloud of the factors that influence a firm's decision to adopt cloud computing.

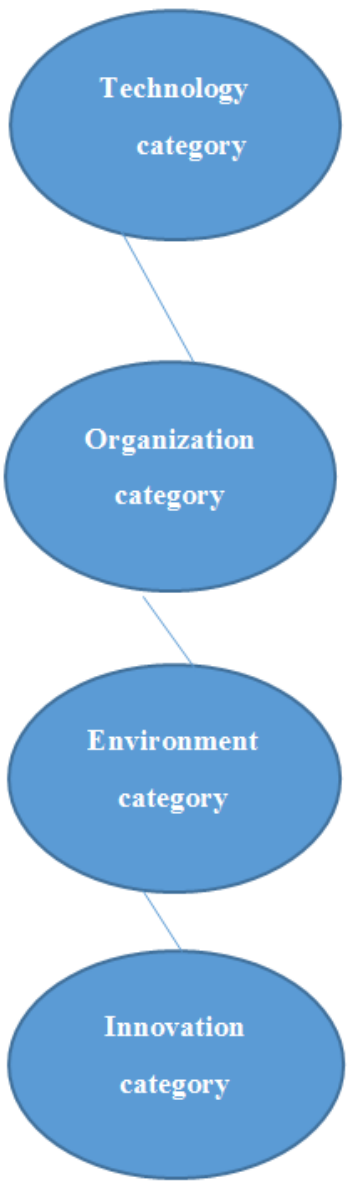

\section{Similar factors}

1) Technology readiness

2) Security, privacy and ethics concern

3) Ease of use and convenience

4) Reliability

5) Previous technological experience

6) Risk analysis
1) Top management support
2) Organization readiness
3) Size of organization
4) Knowledge and training
5) Trust
6) Sharing and collaboration

1) Vendor support

2) Competitive pressure

3) Industry pressure

4) Partner pressure
1) Relative advantage
2) Costs
3) Compatibility
4) Complexity
5) Trialability

Figure-4. Factors affecting the adoption of cloud computing by firms.

\section{Different factors}

\section{Developed countries}

Developing countries

\section{1) Uncertainty}

2) Scalability and flexibility

3) Information processing requirements

4) Information processing capability

1) IT governance and risks

2) Contracting and transaction risks

3) Strategic issues

1) Market scope

2) Quality of services
1) Elasticity

2) Ecological sustainability

3) Data sensitivity
1) Environment readiness

2) Environmental support

3) External pressure 
Figure 4 summarizes the different categories and factors that firms should consider when applying for cloud computing. A total of 36 factors affecting cloud computing in various organizations are mentioned, each stemming from a specific category. Developed and developing countries share 21 similar factors from the main categories including technology, organization, environment and innovation. However, in companies applying for cloud computing, the factors that influence the decision-making process differs significantly between countries with developed and developing economies. Developed countries focused on 9 factors from 3 categories, i.e., 4 from technology, 3 from organization and, 2 dealing with the environment. Factors from developing countries were based on technology and environment categories. For future research, expanding on these different factors to provide a deeper picture of factors influencing cloud computing adoption in companies is prerequisite.

\subsection{The Limitations in Previous Research about Cloud Computing Adoption}

The previous research on cloud computing in developed and developing countries are facing a number of similar challenges such as limitations on the research area, data collection techniques, research methodology, theoretical models, and research objectives.

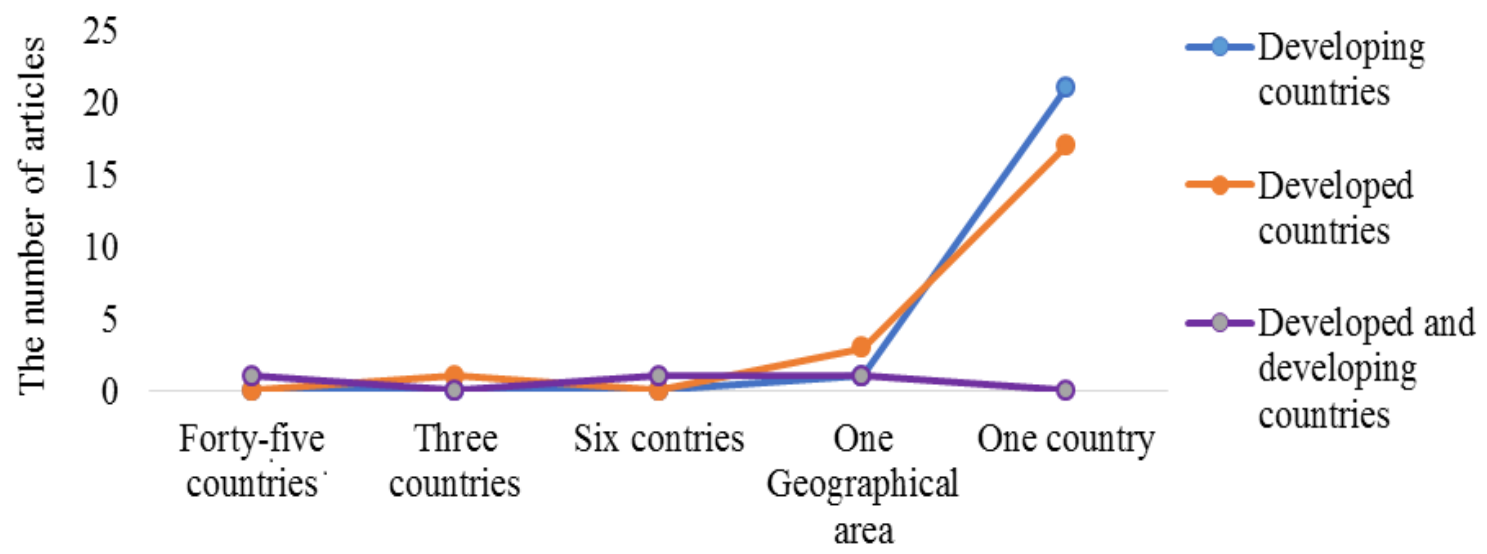

The number of countries/areas collected data in one article

Figure-5. Research area in previous cloud computing research

\subsubsection{Research Area}

Figure 5 indicates that most studies in developed and developing countries conducted data from a single country. Finding from 46 articles included 38 studies with data collection from an individual country (17 from developed countries and 21 from developing countries), 1 study in a developed country collected data from three countries, 1 study in collected data from six countries including developed and developing countries, and only 4 studies data collection followed geographic area. Carreiro and Oliveira [60] conducted an online survey to gather information from firms in Portugal, with the aim to evaluate the effect of leadership components on the adoption of mobile cloud computing. The survey successfully collected results from 154 questionnaires from approximately 2000 participants with managerial positions. Raut, et al. [42] collected data from 660 respondents in India via email. Safari, et al. [28] sent questionnaires to 200 Iranian SMEs via internet and 92 responses were used for analysis. Ming, et al. [14] collected data from 170 SMEs in Sabah in Malaysia. Data collected from a single country is less time-consuming and more cost-effective. Despite this, it is difficult to widely apply results to other countries or other regions $[17,60]$.

\subsubsection{Data Collection Techniques}

Most studies used one method of data collection. Out of 46 research studies, there were 33 studies using online questionnaires, 8 studies used semi-structured interviews and 2 studies used in-depth interviews, and only 1 study 
used mixed questionnaire surveys and in-depth interviews. A large number of studies used online questionnaires to collect data [41] while less studies were conducted through face-to-face semi-structured interviews [13, 38, 46]. Using only one method to collect data can lead to bias in research results.

1. In addition, the sampling method is imperative for conducting studies. There are two methods of sampling commonly used in studies: probabilistic sampling and non-probability sampling. According to Harry and Lipsky [79], "probability sampling consists of simple random sampling, systematic sampling, stratified sampling, and multi stage sampling while in non-probability sampling quota sampling, cluster sampling, purpose sampling, judgment sampling, snow ball sampling, expert sampling and convenience samplings". Each sampling method has different strengths and weaknesses. However, several studies have suggested that selecting probabilities sampling gives better results than the non-probabilistic sampling method. Hassan, et al. [45] indicated that convenient sampling using questionnaire data collection can lead to bias in the object selection method.

This study shows that sample sizes from quantitative studies range from 41 to 660 respondents. Many studies used a small sample size. For example, Hassan [41] collected data from 90 service' SMEs in Malaysia; Budņiks and Didenko [64] obtained data from 150 managers in SMEs in Latvia. In the quantitative studies, the smallest sample size was of 12 and the largest sample size was of 45 interviews. In particular, some studies indicate a limitation on sample size such as that of Abubakar, et al. [46] who collected data from 10 SMEs in Nigeria with only 12 participants. The limitation of sample size in the survey resulted in variation and no detection or bias of voluntary feedback.

\subsubsection{Research Methodology and Theoretical Model}

In Figure 6, quantitative method was the most popular research methodology used in 48 previous research, 36 of which were done in developed and developing countries, total 14 and 22 , respectively. It is clear to see that studies in developed countries used many qualitative method and mix qualitative with quantitative method more than in developing countries. Four research studies used mixed method qualitative with quantitative (3 studies in developed countries and 1 study in all developed and developing country), 6 research studies used a qualitative method ( 4 studies in developed countries and 1 study in developing country). Some studies involving the factors that influence cloud adoption applied quantitative methods [3, 36, 41, 60, 64]. By applying a single research method, data collection is more efficient and less costly, however, this incurs several limitations. Research using qualitative methods often has a small sample size, so the use of such results to generalize the whole population is debatable [79]. In contrast, the quantitative method requires a larger number of samples and shows the general problem of the research object. However, this method does not entirely explain the meaning of the research problem [80].

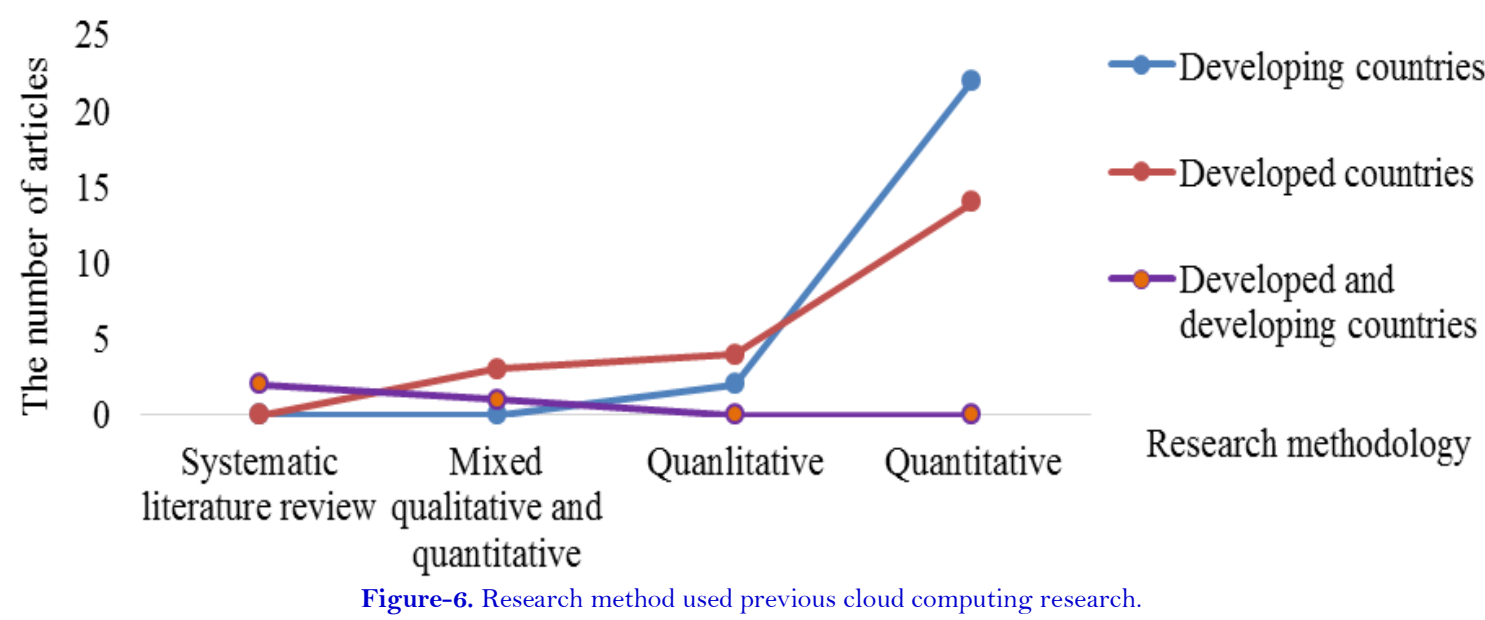


The findings showed that 16 studies using only a single theoretical model are TOE or DOI or TAM. TOE framework was used by Raut, et al. [42]; Harry and Lipsky [79]; Rahman [80]; Venkatesh, et al. [81]; Davis and Venkatesh [82]. DOI theory was used by some studies like Carreiro \& Oliveira [32] and Sello Mokwena [60] while TAM model was applied by Sharma, et al. [58]. The study shows that TOE, DOI, and TAM are frameworks or theoretical models used in cloud computing adoption research to explain issues that impact cloud computing adoption in firms. However, according to Low, et al. [62] "TOE framework may not explicitly point out what the major constructs in the model are, and the variables in each context”. The main limitation of the DOI model is not showing a relationship between the acceptability and the attitude of rejecting innovation [63]. TAM predicts factors influencing an organization or individual's decision on when they will apply the new technology [81]. TAM mentioned two main contents: Perceived Usefulness (PU) and Perceived Ease of Use (PEOU). Davis and Venkatesh [82] stated that PU is "the degree to which a person believes that using a particular system would enhance his or her job performance". PEOU is defined as "the level at which someone should start to believe that a specific system has become effortless". TAM is one of the first models to be applied in new technology adoption studies. However, one large limitation of the model is the lack of consideration of social influencing factors in the model [83]. Hence, using only a single theoretical model it is difficult to fully and systematically explain the research problems [30].

\subsubsection{Research Subject}

Studies from developed and developing countries collected data from a single sector. Hassan [41] focused on service sector while Ooi, et al. [25] collected data from manufacturing firms. Raut, et al. [42] collected data from the private sector in India. Low, et al. [62] conducted data in the high-tech industry and IT. This type of research data collection increases the risk of bias results.

Additionally, a large number of studies only gathered data from one or two subjects within the same company, for example, Tarmidi, et al. [66] collected data from accounting practitioners to determine knowledge and usefulness of cloud computing in Malaysia's SMEs. On the other hand, Kumar, et al. [54] collected data from 271 owner or partners of the SMEs to show factors affecting to adoption of cloud computing such as Relative advantage, Top management support, External pressure, and Vendor support. Low, et al. [62] collected data only from IT staff or managers. Branco, et al. [69] and Sharma, et al. [58] collected data only from IT experts. On the contrary, Cegielski, et al. [11] emphasized that "the use of key respondents is not an ideal means for eliciting highly reliable perceptions." As a result, collecting data from one or two key respondents limits the findings from previous cloud computing studies.

\subsection{A 4-M Recommendation for Future Studies}

After observing the limitations of the previous studies on the application of cloud computing, this paper seeks to recommend 4-M as a more comprehensive alternative for future research on cloud computing adoption in firms, as shown in Figure 7.

Multi-areas: refers to a data collection process from multiple locations within a country and/or from multiple countries. For example, in the same country, data may be collected for the northern, central, and southern regions, or in rural and urban areas. More broadly, data can be collected from countries in the same geographic area as South Asian, North American, South African, etc. Data can also be collected from countries with similar economic characteristics including those that are developed and developing. Collecting data from different regions within the same country or between different countries will give researchers a more comprehensive view of the current enterprise cloud computing adoption. Thus, research results can be replicated in countries with similar conditions. For instance, Gupta, et al. [49] collected primary data from 211 SMEs in India, Singapore, Malaysia, and USA to show a more comprehensive view of the factors influencing the decision to adopt cloud computing in SMEs. Vu, et al. [59] used data from a total of 45 countries for a duration of 5 years, to demonstrate how commercial and 
dependent countries tend to increase cloud adoptions. Countries with developed services also have higher levels of cloud adoption than other countries. Hence, future research data collection should be conducted in various countries.

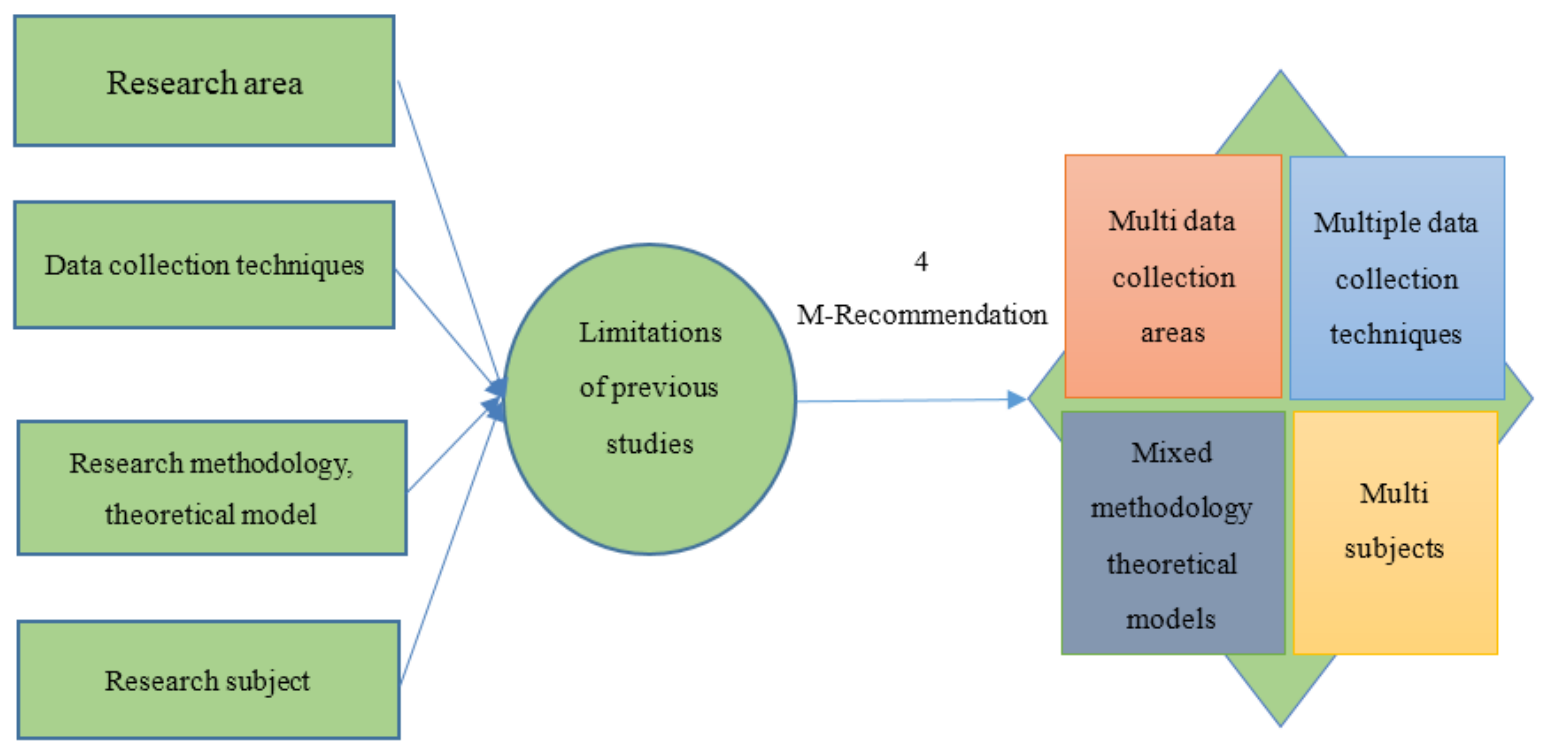

Figure-7. The limitations of previous research and recommendations for future research.

Multiple data collection techniques: Previous cloud computing studies mainly used online surveys and semistructured interview methods to collect data. However, today there is a huge amount of data available. Researchers can currently use different techniques to collect data from the Web such as web crawling, web scraping, google analytics, sensors and Internet of Things (IoT). These data collection techniques are used in many current studies related to information technology. According to Khalil and Fakir [84] "Web crawlers, or spiders, are programs that automatically browse and download web pages by following hyperlinks in a methodical and automated manner". For example, Zhou, et al. [85] based on Web crawler technique to collect data from web mining, with the aim of examining market information in the agricultural sector. The results showed that three types of crawlers assisted in the collection of market data for agricultural products. This market information can help producers have knowledge of agricultural products price, forecasting risk, and guide decision making, etc. Internet of Things (IoT) is considered as a technique of gathering data through the internet in many fields such as health-care, industry, and agriculture [86].

Regarding the sampling method, Hassan [41] supposed that sampling methods should be applied according to certain criteria to avoid limitation in random sampling method. The sampling methods in the studies depend greatly on the budget and time. In addition, sampling methods used in developed and developing countries vary considerably, due to availability of funds. In developed countries, for example they are more financially stable and better equipped to use probabilistic sampling methods for research unlike the less developing economies [87]. However, the research mentions that this sampling method has advantages and disadvantages. Future studies should be based on the research objectives, methods, and resources to select the most appropriate sampling method for the study.

The number of samples depends on many factors such as approach theory, research model, data analysis method, time, and resources [88]. It is difficult to estimate how large the sample size should be. However, the study suggests that arguments should be made with clarity, explaining the reasons for selecting the sample size, implying that the chosen sample size is consistent and suitable with the method and objectives of the study. Yang, et al. [15] explained clearly how they chose their sample and why they chose to sample 173 companies. Thus, the research results will be more reliable. 
Mixed research methodology and theoretical models: this method simply refers to the combination of various research techniques. In previous studies, mixed method will help researchers to achieve more accurate results [12, 17, 30]. The mixed methodology allow for the perception and series of benefits between qualitative and quantitative research simultaneously. Trigueros-Preciado, et al. [38] combined qualitative and quantitative method to collect data from managers group meetings, and 94 industrial SMEs via questionnaires, respectively. This was done to highlight that the lack of knowledge was the main barrier in the adoption of cloud computing in Spain.

In the theoretical model, each of the research theories deals in-depth with certain aspects, for example, TOE refers to three factors (technological, organizational, and environmental), while DOI does not address environmental factors. Some previous studies used combinations of theoretical models such as Oliveira, et al. [31] based their study on DOI-TOE to explore factors affecting the decision to apply cloud computing, 369 responses from firms in manufacturing and services sectors in Portugal were received. Tehrani and Shirazi [65] based on DOI theory, TOE framework and analysis data from 101 decision makers in North American illustrated that the most important factor affecting the enterprise's decision to adopt cloud computing is the understanding of cloud computing by top management. Gangwar, et al. [3] used TAM, TOE and collected data from 280 information technology companies in India to understand the determinants of cloud computing adoption. Tella, et al. [88] used the unified theory of acceptance and utilization of technology (UTAUT) and TAM to show the factors impacting the adoption of cloud computing for online services in Nigerian educational libraries. Therefore, future studies should consider selecting suitable theoretical models that can combine to be applied in the same study.

Multi-subjects: this refers to the diversity of people interviewed in the same company and study should be conducted using different sectors. Cegielski, et al. [11] collected data in manufacturing, logistics, distribution, and retailing sector. Moreover, the implementation of cloud computing at a company does not only involve top management, but also relates to many different departments within the company. For example, the financial accounting department prepare funds for the investment in information technology infrastructure; the bureaucratic office deals with human resources capable of applying for high technology; and the business department devise strategies and plans for company development. Therefore, future studies in relation to cloud computing applications in companies should interview different subjects, including the managers, directors, and IT managers of the various departments, to increase the reliability of the results. Raut, et al. [17] based on the point of view 16 experts in the fields of computer science, cloud computing, software, telecommunications, and managers in the banking and information technology sectors in India and literature reviews, they were able to point out the key factors influencing the decision to adopt cloud computing in MSMEs in India.

\section{MANAGERIAL IMPLICATIONS}

The research shows the factors that influence the organization's adoption of cloud computing. These factors will be useful for managers to make decisions about applying cloud computing in their enterprises. Some important factors managers should consider when applying cloud computing such as Technology readiness, Top management support, Relative advantage, Security, privacy and ethics concern, and Costs. Managers can see the important factors affecting the decision to adopt cloud computing and the risk factors that may be encountered when applying cloud computing. They can build a clear strategy before making a decision to adopt cloud computing. For cloud service providers, they are also aware of the factors that businesses care about when deciding to adopt the service. Therefore, they can establish strategies to develop cloud computing products that suit the needs of their customers. In addition, the study further shows that support from the provider is also a critical factor when businesses decide to adopt cloud computing. In the future, providers need to increase services to support businesses when implementing cloud computing. In addition, from a 4-M recommendation, managers recognize the benefits of multi areas, multiple data collection techniques, mixed methodology and theoretical models, and multi subjects in the studies. This helps them to find suitable research that can be applied in their business fields. 


\section{CONCLUSIONS AND LIMITATIONS}

This study analyzed articles with relevant content related to the factors affecting cloud computing adoption based on the TOE framework and DOI theory. 36 factors affecting cloud computing were identified and grouped into three categories. Technology context consists of Technology readiness, Relative advantage, Security, privacy and ethics concern, Cost, Compatibility, Complexity, Ease of use, Reliability, Trialability, Risk analysis, Data sensitivity, Previous technological experience, Elasticity, Ecological sustainability, Uncertainly and Geo-restriction, Scalability and flexibility, Information processing requirements, and Information processing capability. This study found that Top management support, Knowledge and training, Size of organization, Organization readiness, Sharing and collaboration, Trust, IT governance and risks, Contracting and transaction risks, and Strategic issues were the factors that belong to Organization context. The Environment category includes Vendor support, Competitive pressure, Industry pressure, Government support, Partner pressure, Geo-restriction, Market scope, Quality of services, Environment readiness, and External pressure. Out of a total of 36 factors influencing an enterprise's decision to adopt cloud computing, 21 are discussed both in developed and developing countries, 9 factors are mentioned only in developed countries, and the remaining 6 factors only appear in research in developing countries. This study also provided a picture of the limitations of previous studies on the application of cloud computing in companies such as the barrier of research area, data collection, research method, and research subject. Finally, this study proposed a 4-M recommendation (Multi-areas, Multiple data collection techniques, Mix methodology and theoretical models, and Multi-subjects) for studies that concern applying cloud computing in firms in the future. However, the study failed to mention the differences in factors affecting the decision to apply cloud computing in each field. Hence, the first suggestion will be to explore the factors that affect the adoption of cloud computing in companies to follow different fields. For example, we can compare the differences in the factors that influence the decision to apply cloud computing between service and manufacturing companies. On the other hand, database was conducted only from Google Scholar, Emerald Insight, Spring Link, Science Direct, IEEE Explore. Some studies on the factors affecting cloud computing applications in enterprises can be found in other databases. Therefore, the second suggestion could be extended to other databases which have more articles concerning cloud computing adoption in firms.

Funding: This study received no specific financial support.

Competing Interests: The authors declare that they have no competing interests.

Acknowledgement: All authors contributed equally to the conception and design of the study.

\section{REFERENCES}

[1] A. Evangelinou, M. Ciavotta, D. Ardagna, A. Kopaneli, G. Kousiouris, and T. Varvarigou, "Enterprise applications cloud rightsizing through a joint benchmarking and optimization approach," Future Generation Computer Systems, vol. 78, pp. 102-114, 2018.Available at: https://doi.org/10.1016/j.future.2016.11.002.

[2] I. Mezgár and U. Rauschecker, "The challenge of networked enterprises for cloud computing interoperability," Computers in Industry, vol. 65, pp. 657-674, 2014.Available at: https://doi.org/10.1016/j.compind.2014.01.017.

[3] H. Gangwar, H. Date, and R. Ramaswamy, "Understanding determinants of cloud computing adoption using an integrated TAM-TOE model," Journal of Enterprise Information Management, vol. 28, pp. 107-130, 2015.Available at: https://doi.org/10.1108/jeim-08-2013-0065.

[4] C. Stergiou, K. E. Psannis, B. B. Gupta, and Y. Ishibashi, "Security, privacy \& efficiency of sustainable cloud computing for big data \& IoT," Sustainable Computing: Informatics and Systems, vol. 19, pp. 174-184, 2018.Available at: https://doi.org/10.1016/j.suscom.2018.06.003.

[5] A. Lin and N.-C. Chen, "Cloud computing as an innovation: Percepetion, attitude, and adoption," International Journal of Information Management, vol. 32, pp. 533-540, 2012.Available at: https://doi.org/10.1016/j.ijinfomgt.2012.04.001. 
[6] S. Liu, F. T. Chan, J. Yang, and B. Niu, "Understanding the effect of cloud computing on organizational agility: An empirical examination," International Journal of Information Management, vol. 43, pp. 98-111, 2018.Available at: https://doi.org/10.1016/j.ijinfomgt.2018.07.010.

[7] E. O. Y. Boateng and K. A. Essandoh, "Factors influencing the adoption of cloud computing by small and medium enterprises in developing economies," International Journal of Emerging Science and Engineering, vol. 2, pp. 13-20, 2014.

[8] P. Priyadarshinee, R. D. Raut, M. K. Jha, and B. B. Gardas, "Understanding and predicting the determinants of cloud computing adoption: A two staged hybrid SEM-Neural networks approach," Computers in Human Behavior, vol. 76, pp. 341-362, 2017.Available at: https://doi.org/10.1016/j.chb.2017.07.027.

[9] N. Brender and I. Markov, "Risk perception and risk management in cloud computing: Results from a case study of Swiss companies," International Journal of Information Management, vol. 33, pp. 726-733, 2013.Available at: https://doi.org/10.1016/j.ijinfomgt.2013.05.004.

[10] N. Subramanian, M. D. Abdulrahman, and X. Zhou, "Reprint of "Integration of logistics and cloud computing service providers: Cost and green benefits in the Chinese context," Transportation Research Part E: Logistics and Transportation Review, vol. 74, pp. 81-93, 2015.Available at: https://doi.org/10.1007/s10796-014-9506-5.

[11] C. G. Cegielski, L. A. Jones-Farmer, Y. Wu, and B. T. Hazen, "Adoption of cloud computing technologies in supply chains: An organizational information processing theory approach," The International Journal of Logistics Management, vol. 23, pp. 184-211, 2012.Available at: https://doi.org/10.1108/09574091211265350.

[12] Y. Alshamaila, S. Papagiannidis, and F. Li, "Cloud computing adoption by SMEs in the north east of England: A multiperspective framework," Journal of Enterprise Information Management, vol. 26, pp. 250-275, 2013.Available at: https://doi.org/10.1108/17410391311325225.

[13] O. M. Yigitbasioglu, "External auditors' perceptions of cloud computing adoption in Australia," International Journal of Accounting Information Systems, vol. 18, pp. 46-62, 2015.Available at: https://doi.org/10.1016/j.accinf.2015.09.001.

[14] C. F. Ming, C. K. On, A. Rayner, T. T. Guan, and A. Patricia, "The determinant factors affecting cloud computing adoption by small and medium enterprises (SMEs) in Sabah, Malaysia," Journal of Telecommunication, Electronic and Computer Engineering (JTEC), vol. 10, pp. 83-88, 2018.

[15] Z. Yang, J. Sun, Y. Zhang, and Y. Wang, "Understanding SaaS adoption from the perspective of organizational users: A tripod readiness model," Computers in Human Behavior, vol. 45, pp. 254-264, 2015.Available at: https://doi.org/10.1016/j.chb.2014.12.022.

[16] I. van de Weerd, I. S. Mangula, and S. Brinkkemper, "Adoption of software as a service in Indonesia: Examining the influence of organizational factors," Information \& Management, vol. 53, pp. 915-928, 2016.Available at: https://doi.org/10.1016/j.im.2016.05.008.

[17] R. D. Raut, B. B. Gardas, M. K. Jha, and P. Priyadarshinee, "Examining the critical success factors of cloud computing adoption in the MSMEs by using ISM model," The Journal of High Technology Management Research, vol. 28, pp. 125141, 2017.Available at: https://doi.org/10.1016/j.hitech.2017.10.004.

[18] R. Buyya, C. S. Yeo, S. Venugopal, J. Broberg, and I. Brandic, "Cloud computing and emerging IT platforms: Vision, hype, and reality for delivering computing as the 5th utility," Future Generation Computer Systems, vol. 25, pp. 599-616, 2009.Available at: https://doi.org/10.1016/j.future.2008.12.001.

[19] A. Ali, D. Warren, and L. Mathiassen, "Cloud-based business services innovation: A risk management model," International Journal of Information Management, vol. 37, pp. 639-649, 2017.Available at: https://doi.org/10.1016/j.ijinfomgt.2017.05.008.

[20] M. Armbrust, A. Fox, R. Griffith, A. D. Joseph, R. Katz, A. Konwinski, G. Lee, D. Patterson, A. Rabkin, and I. Stoica, "A view of cloud computing," Communications of the ACM, vol. 53, pp. 50-58, 2010.

[21] L. Novais, J. M. Maqueira, and Á. Ortiz-Bas, "A systematic literature review of cloud computing use in supply chain integration," Computers \& Industrial Engineering, vol. 129, pp. 296-314, 2019.Available at: https://doi.org/10.1016/j.cie.2019.01.056. 
[22] M. A. Abd Elmonem, E. S. Nasr, and M. H. Geith, "Benefits and challenges of cloud ERP systems-A systematic literature review," Future Computing and Informatics Journal, vol. 1, pp. 1-9, 2016.Available at: https://doi.org/10.1016/j.fcij.2017.03.003.

[23] A. Ozu, N. Kasuga, and H. Morikawa, "Cloud computing and its impact on the Japanese macroeconomy-its oligopolistic market characteristics and social welfare," Telecommunications Policy, vol. 44, p. 101852, 2020.Available at: https://doi.org/10.1016/j.telpol.2019.101852.

[24] W.-H. L. Hsu, "Conceptual framework of cloud computing governance model-an education perspective," IEEE Technology and Engineering Education (ITEE), vol. 7, pp. 12-16, 2012.

[25] K.-B. Ooi, V.-H. Lee, G. W.-H. Tan, T.-S. Hew, and J.-J. Hew, "Cloud computing in manufacturing: The next industrial revolution in Malaysia?," Expert Systems with Applications, vol. 93, pp. 376-394, 2018.Available at: https://doi.org/10.1016/j.eswa.2017.10.009.

[26] G. L. Tornatzky and M. Fleischer, The processes of technological innovation. Massachusetts: Lexington Books, 1990.

[27] A. Khayer, M. S. Talukder, Y. Bao, and M. N. Hossain, "Cloud computing adoption and its impact on SMEs' performance for cloud supported operations: A dual-stage analytical approach," Technology in Society, vol. 60, p. 101225, 2020.Available at: https://doi.org/10.1016/j.techsoc.2019.101225.

[28] F. Safari, N. Safari, A. Hasanzadeh, and A. R. Ghatari, "Factors affecting the adoption of cloud computing in small and medium enterprises," International Journal of Business Information Systems, vol. 20, pp. 116-137, 2015.Available at: https://doi.org/10.1504/ijbis.2015.070894.

[29] E. Rogers, Diffusions of innovations. New York: Free Press, 2003.

[30] M. I. Baig, L. Shuib, and E. Yadegaridehkordi, "Big data adoption: State of the art and research challenges," Information Processing \& Management, vol. 56, p. 102095, 2019.Available at: https://doi.org/10.1016/j.ipm.2019.102095.

[31] T. Oliveira, M. Thomas, and M. Espadanal, "Assessing the determinants of cloud computing adoption: An analysis of the manufacturing and services sectors," Information \& Management, vol. 51, pp. 497-510, 2014.Available at: https://doi.org/10.1016/j.im.2014.03.006.

[32] S. Mokwena, "Factors affecting the adoption of software as a service in South African small medium enterprises," presented at the Open Innovations Conference, 2018.

[33] P.-F. Hsu, K. L. Kraemer, and D. Dunkle, "Determinants of e-business use in US firms," International Journal of Electronic Commerce, vol. 10, pp. 9-45, 2006.

[34] L. Victor, "Systematic reviewing," Social Research Update, vol. 54, pp. 1-4, 2008.

[35] K. Dikert, M. Paasivaara, and C. Lassenius, "Challenges and success factors for large-scale agile transformations: A systematic literature review," Journal of Systems and Software, vol. 119, pp. 87-108, 2016.Available at: https://doi.org/10.1016/j.jss.2016.06.013.

[36] P.-F. Hsu, S. Ray, and Y.-Y. Li-Hsieh, "Examining cloud computing adoption intention, pricing mechanism, and deployment model," International Journal of Information Management, vol. 34, pp. 474-488, 2014.Available at: https://doi.org/10.1016/j.ijinfomgt.2014.04.006.

[37] M. A. Hani and A. H. A. Badi, "Critical success factors affecting the adoption of cloud computing in Oil and Gas industry in Oman," presented at the 3rd MEC International Conference on Big Data and Smart City, ICBDSC, 2016.

[38] S. Trigueros-Preciado, D. Pérez-González, and P. Solana-González, "Cloud computing in industrial SMEs: Identification of the barriers to its adoption and effects of its application," Electronic Markets, vol. 23, pp. 105-114, 2013.Available at: https://doi.org/10.1007/s12525-012-0120-4.

[39] T. Lynn, X. Liang, A. Gourinovitch, J. Morrison, G. Fox, and P. Rosati, "Understanding the determinants of cloud computing adoption for high performance computing," in Proceedings of the 51st Hawaii International Conference on System Sciences, 2018, pp. 3894-3903. 
[40] A. Gutierrez, E. Boukrami, and R. Lumsden, "Technological, organisational and environmental factors influencing managers' decision to adopt cloud computing in the UK," Journal of Enterprise Information Management, vol. 28, pp. 788807, 2015.Available at: https://doi.org/10.1108/jeim-01-2015-0001.

[41] H. Hassan, "Organisational factors affecting cloud computing adoption in small and medium enterprises (SMEs) in service sector," Procedia Computer Science, vol. 121, pp. 976-981, 2017.Available at: https://doi.org/10.1016/j.procs.2017.11.126.

[42] R. D. Raut, P. Priyadarshinee, B. B. Gardas, and M. K. Jha, "Analyzing the factors influencing cloud computing adoption using three stage hybrid SEM-ANN-ISM (SEANIS) approach," Technological Forecasting and Social Change, vol. 134, pp. 98-123, 2018.Available at: https://doi.org/10.1016/j.techfore.2018.05.020.

[43] P. Priyadarshinee, R. D. Raut, M. K. Jha, and S. S. Kamble, "A cloud computing adoption in Indian SMEs: Scale development and validation approach," The Journal of High Technology Management Research, vol. 28, pp. 221-245, 2017.Available at: https://doi.org/10.1016/j.hitech.2017.10.010.

[44] A. Habahbeh, S. O. Fadiya, and M. Akkaya, "Factors influencing SMEs CloudERP adoption: A test with generalized linear model and artificial neural network," Data in Brief, vol. 20, pp. 969-977, 2018.Available at: https://doi.org/10.1016/j.dib.2018.07.012.

[45] H. Hassan, M. H. M. Nasir, N. Khairudin, and I. Adon, "Factors influencing cloud computing adoption in small medium enterprises," Journal of Information and Communication Technology, vol. 16, pp. 21-41, 2017.Available at: https://doi.org/10.32890/jict2017.16.1.2.

[46] A. Abubakar, J. M. Bass, and I. Allison, "Cloud computing: Adoption issues for Sub-Saharan African SMEs," The Electronic Journal of Information Systems in Developing Countries, vol. 62, pp. 1-17, 2014.Available at: https://doi.org/10.1002/j.1681-4835.2014.tbo0439.x.

[47] R. Seethamraju, "Adoption of software as a service (SaaS) enterprise resource planning (ERP) systems in small and medium sized enterprises (SMEs)," Information Systems Frontiers, vol. 17, pp. 475-492, 2015.Available at: https://doi.org/10.1007/s10796-014-9506-5.

[48] O. Sohaib, M. Naderpour, W. Hussain, and L. Martinez, "Cloud computing model selection for e-commerce enterprises using a new 2-tuple fuzzy linguistic decision-making method," Computers \& Industrial Engineering, vol. 132, pp. 47-58, 2019.Available at: https://doi.org/10.1016/j.cie.2019.04.020.

[49] P. Gupta, A. Seetharaman, and J. R. Raj, "The usage and adoption of cloud computing by small and medium businesses," International Journal of Information Management, vol. 33, pp. 861-874, 2013.Available at: https://doi.org/10.1016/j.ijinfomgt.2013.07.001.

[50] R. El-Gazzar, E. Hustad, and D. H. Olsen, "Understanding cloud computing adoption issues: A Delphi study approach," Journal of Systems and Software, vol. 118, pp. 64-84, 2016.Available at: https://doi.org/10.1016/j.jss.2016.04.061.

[51] N. Alkhater, R. Walters, and G. Wills, "An empirical study of factors influencing cloud adoption among private sector organisations," Telematics and Informatics, vol. 35, pp. 38-54, 2018.Available at: https://doi.org/10.1016/j.tele.2017.09.017.

[52] L. M. Hasan, L. A. Zgair, A. A. Ngotoye, H. N. Hussain, and C. Najmuldeen, "A review of the factors that influence the adoption of cloud computing by small and medium enterprises," School Journal Economics Business Management, vol. 2, pp. 842-848, 2015.

[53] A. N. Salleh, H. Hussin, A. M. Suhaimi, and A. A. Ali, "Systematic literature review of cloud computing adoption and impacts among small medium enterprises (SMEs)," presented at the International Conference on Information and Communication Technology Muslim World (ICT4M), 2018.

[54] D. Kumar, H. V. Samalia, and P. Verma, "Factors influencing cloud computing adoption by small and medium-sized enterprises (SMEs) In India," Pacific Asia Journal of the Association for Information Systems, vol. 9, pp. 25-48, 2017. 
[55] R. M. Al-Dwairi, N. Al-Tweit, and K. Zyout, "Factors influencing cloud computing adoption in small and medium Ecommerce enterprises in Jordan," in Proceedings of the 2018 International Conference on Internet and e-Business, 2018, pp. $73-78$.

[56] K. Karkonasasi, A. S. Baharudin, B. Esparham, S. A. Mousavi, and A. Suhaimi Baharudin, "Adoption of cloud computing among enterprises in Malaysia," Indian Journal of Science and Technology, vol. 9, pp. 1-7, 2016.Available at: https://doi.org/10.17485/ijst/2016/v9i48/88128.

[57] A. Saedi and N. Lahad, "An integrated theoretical framework for cloud computing adoption by small and medium-sized enterprises," presented at the Pacific Asia Conference on Information Systems, 2013.

[58] S. K. Sharma, A. H. Al-Badi, S. M. Govindaluri, and M. H. Al-Kharusi, "Predicting motivators of cloud computing adoption: A developing country perspective," Computers in Human Behavior, vol. 62, pp. 61-69, 2016.Available at: https://doi.org/10.1016/j.chb.2016.03.073.

[59] K. Vu, K. Hartley, and A. Kankanhalli, "Predictors of cloud computing adoption: A cross-country study," Telematics and Informatics, vol. 52, p. 101426, 2020.Available at: https://doi.org/10.1016/j.tele.2020.101426.

[60] H. Carreiro and T. Oliveira, "Impact of transformational leadership on the diffusion of innovation in firms: Application to mobile cloud computing," Computers in Industry, vol. 107, pp. 104-113, 2019.Available at: https://doi.org/10.1016/j.compind.2019.02.006.

[61] V. M. Dincă, A. M. Dima, and Z. Rozsa, "Determinants of cloud computing adoption by Romanian SMEs in the digital economy," Journal of Business Economics and Management, vol. 20, pp. 798-820, 2019.Available at: https://doi.org/10.3846/jbem.2019.9856.

[62] C. Low, Y. Chen, and M. Wu, "Understanding the determinants of cloud computing adoption," Industrial Management E Data Systems, vol. 111, pp. 1006-1023, 2011 .Available at: https://doi.org/10.1108/02635571111161262.

[63] L. Y. Qian, A. S. Baharudin, and A. K. Jebna, "Factors affecting the adoption of enterprise resource planning (ERP) on cloud among small and medium enterprises (SMEs) in Penang, Malaysia," Journal of Theoretical and Applied Information Technology, vol. 88, pp. 398-409, 2016.

[64] L. Budņiks and K. Didenko, "Factors determining application of cloud computing services in Latvian SMEs," ProcediaSocial and Behavioral Sciences, vol. 156, pp. 74-77, 2014.Available at: https://doi.org/10.1016/j.sbspro.2014.11.122.

[65] S. R. Tehrani and F. Shirazi, "Factors influencing the adoption of cloud computing by small and medium size enterprises (SMEs)," Human Interface Manag. Information, Knowledge Application Services, vol. 8522, pp. 631-642, 2014.

[66] M. Tarmidi, S. Z. A. Rasid, B. Alrazi, and R. A. Roni, "Cloud computing awareness and adoption among accounting practitioners in Malaysia," Procedia-Social and Behavioral Sciences, vol. 164, pp. 569-574, 2014.Available at: https://doi.org/10.1016/j.sbspro.2014.11.147.

[67] A. Wachanga and J. R. A. Ndiege, "Adoption of cloud computing by small and medium enterprises in Nairobi County, Kenya," International Journal of Humanities and Social Science, vol. 1, pp. 44-50, 2018.

[68] Q. Zheng, D. Gu, C. Liang, and Y. Fang, "Impact of a firm's physical and knowledge capital intensities on its selection of a cloud computing deployment model," Information \& Management, vol. 57, p. 103259, 2020.Available at: https://doi.org/10.1016/j.im.2019.103259.

[69] J. T. Branco, F. de Sá-Soares, and A. L. Rivero, "Key issues for the successful adoption of cloud computing," Procedia Computer Science, vol. 121, pp. 115-122, 2017.Available at: https://doi.org/10.1016/j.procs.2017.11.016.

[70] M. Parent and B. H. Reich, "Governing information technology risk," California Management Review, vol. 51, pp. 134152, 2009.Available at: https://doi.org/10.2307/41166497.

[71] N. Levenburg, S. R. Magal, and P. Kosalge, "An exploratory investigation of organizational factors and e-business motivations among SMFOEs in the US," Electronic Markets, vol. 16, pp. 70-84, 2006.Available at: https://doi.org/10.1080/10196780500491402.

[72] C. S. Yap, "Distinguishing characteristics of organizations using computers," Information \& Management, vol. 18, pp. 97-107, 1990.Available at: https://doi.org/10.1016/0378-7206(90)90056-n. 
[73] S. Goode and K. Stevens, "An analysis of the business characteristics of adopters and non-adopters of World Wide Web technology," Information Technology and Management, vol. 1, pp. 129-154, 2000.

[74] K. Zhu, K. Kraemer, and S. Xu, "Electronic business adoption by European firms: A cross-country assessment of the facilitators and inhibitors," European Journal of Information Systems, vol. 12, pp. 251-268, 2003.Available at: https://doi.org/10.1057/palgrave.ejis.3000475.

[75] S. Chopra and P. Meindl, "E-business and the supply chain, supply chain management," ed Upper Saddle River, NJ: Prentice-Hall, 2001, pp. 33-37.

[76] J. Repschlaeger, K. Erek, and R. Zarnekow, "Cloud computing adoption: An empirical study of customer preferences among start-up companies," Electronic Markets, vol. 23, pp. 115-148, 2013.

[77] M. N. Alsharari, M. Al-Shboul, and S. Alteneiji, "Implementation of cloud ERP in the SME: Evidence from UAE," Journal of Small Business and Enterprise Development, vol. 27, pp. 299-327, 2020.

[78] E. M. Rogers, "Lessons for guidelines from the diffusion of innovations," The Joint Commission Journal on Quality Improvement, vol. 2 1, pp. 324-328, 1995.Available at: https://doi.org/10.1016/s1070-3241(16)30155-9.

[79] B. Harry and M. Lipsky, "Qualitative research on special education teacher preparation. In Handbook of Research on Special Education Teacher Preparation," ed: Taylor and Francis, 2014, pp. 445-460.

[80] S. M. Rahman, "The advantages and disadvantages of using qualitative and quantitative approaches and methods in language testing and assessment research: A literature review," Journal of Education and Learning, vol. 6, pp. 102-112, 2016.

[81] V. Venkatesh, M. G. Morris, D. B. Gordon, and F. D.Davis, "User acceptance of information technology: Toward a unified view," MIS Quarterly, vol. 27, pp. 425-478, 2003.

[82] F. D. Davis and V. Venkatesh, "A critical assessment of potential measurement biases in the technology acceptance model: Three experiments," International Journal of Human-Computer Studies, vol. 45, pp. 19-45, 1996.Available at: https://doi.org/10.1006/ijhc.1996.0040.

[83] F. D. Davis, R. P. Bagozzi, and P. R. Warshaw, "User acceptance of computer technology: A comparison of two theoretical models," Management Science, vol. 35, pp. 982-1003, 1989.Available at: https://doi.org/10.1287/mnsc.35.8.982.

[84] S. Khalil and M. Fakir, "RCrawler: An R package for parallel web crawling and scraping," SoftwareX, vol. 6, pp. 98106, 2017.Available at: https://doi.org/10.1016/j.softx.2017.04.004.

[85] J. Zhou, C. Cheng, L. Kang, and R. Sun, "Integration and analysis of agricultural market information based on Web mining," IFAC-Papers Online, vol. 51, pp. 778-783, 2018.Available at: https://doi.org/10.1016/j.ifacol.2018.08.101.

[86] Y. Al-Hadhrami and F. K. Hussain, "Real time dataset generation framework for intrusion detection systems in IoT," Future Generation Computer Systems, vol. 108, pp. 414-423, 2020.Available at: https://doi.org/10.1016/j.future.2020.02.051.

[87] N. Khan, "Critical review of sampling techniques in the research process in the world," SSRN, vol. 1, pp. 1-37, 2020.

[88] A. Tella, S. C. Ukwoma, and I. K. Adeniyi, "A two models modification for determining cloud computing adoption for web-based services in academic libraries in Nigeria," The Journal of Academic Librarianship, vol. 46, p. 102255, 2020.Available at: https://doi.org/10.1016/j.acalib.2020.102255. 